1. Auf Lebensmittel, Gesundheitspflege, Handel etc. bezügliche. 369

\title{
Die Erkennung von Finnen in Wurst oder zerhacktem Fleisch
}

bot bisher ziemliche Schwierigkeiten. Schmidt-Mühlheim*) lässt nun zur Ueberwindung dieser Schwierigkeiten eine hinreichend grosse Probe des Untersuchungsobjectes mit dem $6-8$ fachen Raumtheile künstlichem Magensaft einige Stunden lang bei $40^{\circ} \mathrm{C}$. digeriren. Hierdurch wird das Fleisch verdaut, während sich das Fett in einer mehr oder minder starken Schicht an der Oberfläche der Flüssigkeit sammelt. Die Blasenkörper der Finnen setzen dagegen wie bekannt der Verdauung einen ausserordentlichen Widerstand entgegen. Nur die Blasenwand derselben wird angegriffen, während die Kopfzapfen, besonders aber die Köpfe and Hakenkränze vollkommen unversehrt bleiben und sich vermöge ihres hohen specifischen Gewichtes bald auf dem Grunde des Gefässes als etwa reiskorngrosse, weisse Körper ansammeln, an denen sich erst nach tagelanger Einwirkung des Magensaftes Spuren beginnender Au:lösung bemerkbar machen.

Bei genauer Betrachtung des so erhaltenen Bodensatzes unter Wasser bemerkt man an den weissen Körpern, welche von Finnen herstammen, eine stark ausgeprägte Querfurchung, sowie den in den hohlen Kopfzapfen eingezogenen oder aus demselben vorgestülpten, unversehrten Finnenkopf, welcher mittelst Präparirnadel leicht isolirt und in verdünntem Glycerin bei etwa 20 facher Vergrösserung mikroskopirt werden kann.

Dies Verfahren soll nach Versicherung des Verfassers selbst vereinzelte Finnen noch vorzüglich erkennen lassen.

Untersuchung von Butter. Zur Bestimmung der scheinbaren Dichte des Butterfettes bei $100^{\circ} \mathrm{C}$. hat $G$. A $m b \ddot{b} h l^{*}$ ) einen Apparat angegeben, dessen wesentlichster Theil genau übereinstimmt mit der Sox h let'schen Vorrichtung zur Bestimmung des specifischen Gewichtes der Aetherfettlösung bei der aräometrischen Fettbestimmung in der Milch***). Das Soxhlet'sche Kühlrohr dient bei Amb ühl als Dampfmantel. Die ganze Vorrichtung dürfte hiernach ohne Weiteres verständlich sein.

Zur Entdeckung künstlicher Farbstoffe in Butter und anderen Fetten hat $\mathrm{Edward} W$. Martin $\dagger$ ) folgendes Verfahren angegeben: Man löst 2 Theile Schwefelkoblenstoff in 15 Theilen Methylalkohol durch

*) Deutsche Med -Ztg. durch Pharm. Zeitschrift für Russland 24, 785.

**) Chem.-Ztg. 12, 392.

***) Siehe diese Zeitschrift 20,452 und Abbildung 6 auf Tafel III ebendaselbst.

f) The Analyst 12, 70. Vergleiche die ältere Modification des Verfahrens in dieser Zeitsehrift 26, 389. 